\title{
The adaptive geometry of boreal conifers
}

\author{
D. J. Walker ${ }^{1}$ and N. C. Kenkel \\ Department of Botany, University of Manitoba, Winnipeg, Manitoba, Canada R3T 2N2. \\ ${ }^{1}$ Corresponding author.E-mail: djwalkr@cc.umanitoba.ca
}

Keywords: Anechoic surface, Canopy reflectance, Fractal, Landsat, Leaf area index, Primary productivity, Remote sensing, Tree architecture, Vegetation index.

\begin{abstract}
Accurate and unbiased radiative energy transfer models are critical to our understanding of ecosystem primary productivity, carbon cycling, and climate change. Much of the current research in this area is based on models parameterized for grasslands and broadleaf forests. However, many temperate montane and boreal forests are dominated by conifers, which present unique challenges to modellers. We propose two fundamentally different strategies by which plant canopies optimize solar radiation interception. Laminar canopies (e.g., grasslands, broadleaf trees) are 'solar panels' that directly intercept incoming radiant energy. By contrast, conifer canopies are conical anechoic ('without echo') surfaces that intercept radiant energy by scattering it through the canopy. The properties of anechoic surfaces are well known in acoustical and electrical engineering, but have not been applied in environmental biophysics. We discuss the physical principles of anechoic surfaces, and demonstrate how these principles apply to conifer trees and canopies. A key feature of anechoic interception is low radiance over all wavelengths, which is an emergent property of the system. Using empirical data from boreal forest stands in Riding Mountain National Park (Manitoba, Canada), we demonstrate that conifer canopies have very low near-infrared radiance compared to laminar broadleaf canopies. Vegetation index values for conifers are thereby reduced, resulting in underestimates of primary productivity and other biophysical parameters. We also discuss the adaptive significance of boreal conifer geometry, and consider factors driving selection of laminar versus anechoic canopy architectures.
\end{abstract}

Abbreviations: LAI - leaf area index, NDVI - normalized difference vegetation index, NIR - near infrared, PAR photosynthetically active radiation, SR - simple ratio.

\section{Introduction}

Over the past decade, the modelling of carbon flux has become a central focus of research in boreal ecosystems (Sellers et al. 199, Brown et al. 2000). Such models require accurate and unbiased estimates of ecoregional photosynthetic rates (carbon-fixation), primary productivity, and phytomass (Middleton et al. 1997, Gholz et al. 1991). Boreal forests, which occupy about $20 \%$ of the world's landmass, are dominated by conifers (Sprugel 1989, Middleton et al. 1997, McDonald et al. 1998). However, forest canopy radiative transfer models are specific to broadleaf trees (Norman and Jarvis 1975, Hall et al. 1995), and the derivation of biophysical productivity indices is based on empirical data from grasslands and broadleaf forests (Jordan 1969, Rouse et al. 1973). Broadleaf trees use a 'solar panel' approach to light capture, arranging their leaves in horizontal laminar layers within the canopy (Sprugel 1989, Norman and Welles 1983). This is a very efficient strategy for capturing direct solar radiation (Horn 1971, Hall et al. 1995). By contrast, conifers have conical crowns containing clusters of needle-shaped leaves, making them appear poorly adapted for optimal light capture (Bond 1989, Dalla-Tea and Jokela 1991). Given this fundamental difference in crown architecture, it is not unreasonable to suggest that existing biophysical models might produce biased results when applied to conifer forests (cf. Nelson 1997).

Numerous studies have demonstrated that conifer and broadleaf canopies 'behave' very differently. The optical properties of conifers vary with scale (Williams 1991), making phytomass estimation unreliable and subject to considerable error (Hall et al. 1995). Prediction of conifer canopy light extinction as a function of the leaf area index (LAI) is also problematic (Norman and Jarvis 1975, Gholz et al. 1991), as is the use of biophysical indices to estimate primary productivity (Ranson and Williams 1992, Chen 1996a, Liu et al. 1997). In satellite images (e.g., Landsat thematic mapper), closed conifer stands are characterized by low reflectance over all wavelengths (Ranson and Williams 1992), indicating a strongly ab- 
sorptive canopy. Explanations for this observation are vague, and include 'canopy heterogeneity' (Gholz et al. 1991, Rowe 1993) and 'needle aggregation and angle' (Sprugel 1989, Sampson and Smith 1993). Another vague term, the 'shadowing' effect of conifer canopies, has been used to explain away errant estimates of biophysical parameters (Colwell 1974, Hall et al. 1995). These observations invite an important question: why do conifers cast such a deep shade, especially in portions of the spectrum where no pigments exist to absorb the incoming radiation? To our knowledge, no plausible mechanism has been forthcoming to explain the scale-related optical behaviour of conifers across the radiative spectrum.

Basic tree architecture is determined by fixed genetic rules (Tomlinson 1983, Bégin and Filion 1999). The conical crown and needle-like leaves of conifers are presumably evolutionarily adaptive, as otherwise they would not have been selected for (Horn 1971, Farnsworth and Niklas 1995). Indeed, the dominance of gymnosperms in many temperate ecosystems (e.g., the boreal and Pacific coast forests of North America) is testament to the adaptive significance of the conifer architecture (Bond 1989, Sprugel 1989).

In this paper, a mechanism for radiant energy capture based on wave physics is proposed to explain the scalerelated optical properties of conifers. Specifically, we postulate that:

- Conifers are anechoic (literally, 'without echo') surfaces that are strongly absorptive over all wavelengths of incident radiant energy.

- The anechoic structure of conifers is an emergent property that is reinforced by a 'cone-on-cone' selfsimilarity across scales, from stands to individual trees to component branches, shoots and needles.

- Boreal climates favour the anechoic canopy architecture as an efficient strategy for radiant energy capture.

- Biophysical productivity estimation assumes that the ratio of red to near infrared radiance declines as biomass increases. But because conifer canopies are strongly absorptive over all wavelengths, biophysical indices will generally underestimate boreal forest primary productivity.

\section{Strategies for light capture}

We recognize two fundamentally different strategies of light capture by plant canopies (Fig. 1). Laminar canopies (e.g., grasslands, broadleaf tree canopies) optimize light capture through direct interception and absorption. By contrast, conical anechoic surfaces (e.g., conifer tree canopies) intercept light by scattering it through the canopy.

\section{Laminar interception}

A flat laminar surface is an optimal strategy for the direct interception and absorption of radiant solar energy. This 'solar panel' approach is characteristic of broadleaf forests and grasslands. In laminar canopies, an efficient arrangement of photosynthetic pigment promotes absorption of photosynthetically active radiation (PAR) while minimizing backscattering (Myers 1983). Conversely, the lack of near-infrared (NIR) absorptive pigments renders laminar surfaces highly reflective in these wavelengths (Ranson and Williams 1992). NIR reflectance therefore increases with phytomass, i.e., as a multi-layered laminar interception surface develops (Colwell 1974).

In broadleaf forests, light interception often occurs over several discrete laminar layers (Lieffers et al. 1999).
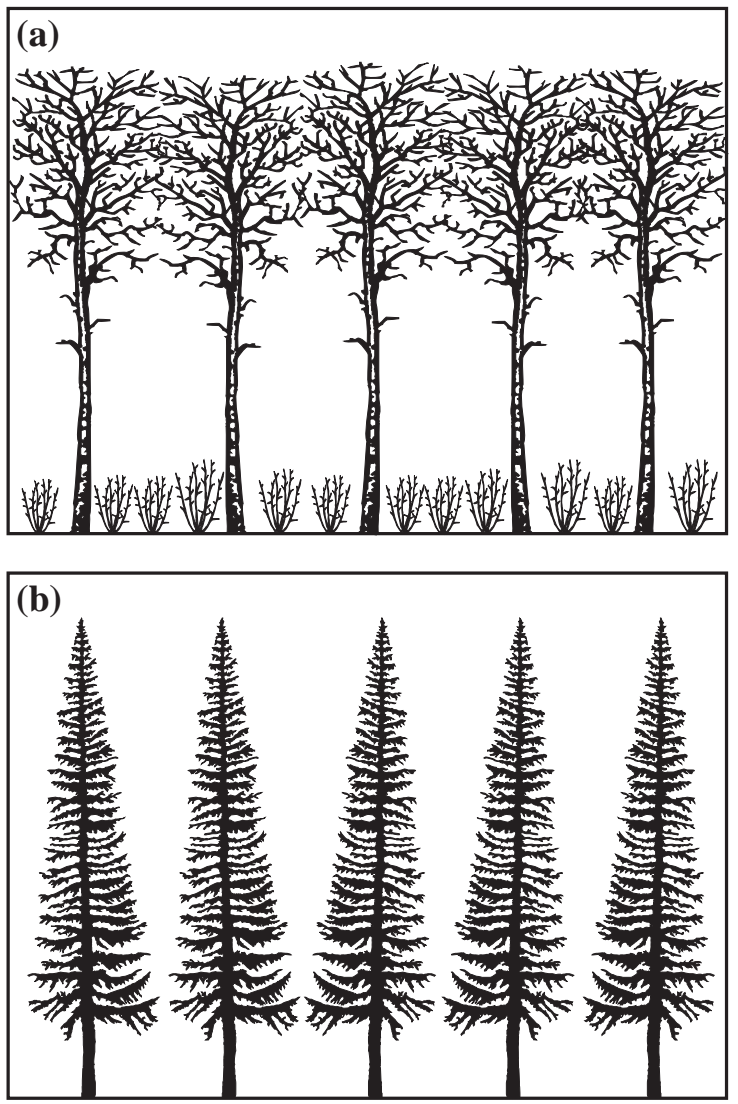

Figure 1. Contrasting canopy architectures for light interception. (a) Laminar interception: broadleaf forest, showing laminar canopy and understory layers; (b) Anechoic interception: conifer forest, showing conical tree crowns. 
Although vertical stratification of laminar canopies increases total absorption, self-shading restricts the number of layers present (Norman and Welles 1983). A typical laminar leaf layer casts a deep shadow (umbral shade) to a distance of about 100 leaf diameters from the point of interception. A partial shadow (penumbral shade) is cast at greater distances, allowing development of a second layer (Horn 1971). Maximal photosynthesis for an idealized multilayer laminar canopy occurs at a leaf area index (LAI) of 1.6. In typical broadleaf forests leaf angles are rarely perfectly horizontal and LAI values of 5 or higher are often observed (Horn 1971, Sprugel 1989).

In laminar canopies, a predictable relationship exists between LAI and the PAR extinction coefficient $k$. This relationship is commonly modelled using the Beer-Lambert negative power law:

$\mathrm{I} / \mathrm{I}_{\mathrm{O}}=\mathrm{e}^{-k \mathrm{LAI}}$

where $I_{0}$ is the incident PAR. The equation is simply inverted to obtain an estimate of LAI from an empirically derived $k$-value (Lieffers et al. 1999). This model assumes that leaves are randomly located in the canopy, but empirical corrections are available to account for non-random or clustered distributions of leaves (Norman and Welles 1983, Gholz et al. 1991). In laminar canopies, leaf area and foliar biomass are tightly coupled to canopy transmittance and photosynthetic efficiency. It is this architecturally determined relationship that is exploited by the Beer-Lambert equation.

\section{Anechoic interception}

We propose that light interception and capture by boreal conifers utilizes an anechoic ('without echo') strategy. In acoustics and electrical engineering, echo reflection occurs when a wave propagating in one medium encounters a second medium of greater impedance (Pierce 1981). The magnitude of reflection is proportional to differences in impedance between the two media (Van Heuvelen 1986). For waves propagated in a hollow tube, anechoic termination involves attenuating mechanisms that cause the amplitude of the generated wave to decrease exponentially with wave propagation distance $x$, following:

$$
e^{-\alpha x}
$$

where $\alpha$ is a frequency-dependent quantity. A tube has anechoic properties if the length $(L)$ through which the wave passes is sufficiently long:

$e^{-\alpha L}<<1$
In practical applications, anechoic termination for a tube of finite length is achieved when the attenuation per unit length increases slowly, following the relation:

$$
\exp \left(-2 \int_{0}^{L} \alpha d x\right)<<1
$$

When $L$ is sufficiently large, the amount of echo is minimal since slow attenuation (tapering) greatly reduces partial wave reflection.

The anechoic property of cones or tapers has been exploited in the design of sound chambers, transmission lines, and electromagnetic test facilities (Beranek and Sleeper 1946, Klopfenstein 1952, Holloway et al. 1997). To obtain an efficient anechoic surface, cones must be tightly packed and cone length must be many times greater than the wavelength of the energy to be absorbed (Holloway et al. 1997). Cone angle can vary from $8^{\circ}$ to $22^{\circ}$, with a reported optimum of $12.5^{\circ}$ (Bornkessel and Wiesbeck 1996, Koidan et al. 1972). To maximize absorption, cones should be constructed of a material dense enough to absorb the incident waves, but not so dense as to result in cone tip reflection (Holloway et al. 1997, Koidan et al. 1972). In engineering applications, density is manipulated by mixing materials of different dielectric properties.

Anechoic surfaces can also absorb or 'capture' radiant energy, as recently demonstrated for sheets of 'black' silicon (Fig. 2a). This anechoic material, which consists of cones $10-12 \mu \mathrm{m}$ in height, absorbs substantially more incident radiation than typical laminar silicon (Her et al. 1998). A light wave entering the cone interstices 'bounces' off the tapered surfaces and is reflected inward, resulting in multiple reflections. Each reflection results in partial absorption as the energy contacts the denser cone material. Because very little of the incident energy survives these numerous reflections, radiance from an anechoic surface is very low (Holloway et al. 1997). We hypothesize that boreal conifers use this light 'capture' strategy: note the striking resemblance between anechoic 'black' silicon and a dense white spruce canopy (Fig. 2b). The tapered conical architecture of boreal conifers is thus highly adaptive, resulting in an anechoic canopy that efficiently scatters and absorbs radiant energy. Transmission within the interstices of tree crowns is high (cf. Canham et al. 1999), but once a radiant energy wave strikes the canopy it is scattered downward and ultimately absorbed. High absorption occurs over all wavelengths, including NIR. This light 'capture' strategy is fundamentally different from that used by broadleaf species, suggesting that laminar canopy transmission models 
Figure 2. (a) 'Black' silicon, image courtesy of Eric Mazur; (b) Aerial view of a boreal white spruce stand.
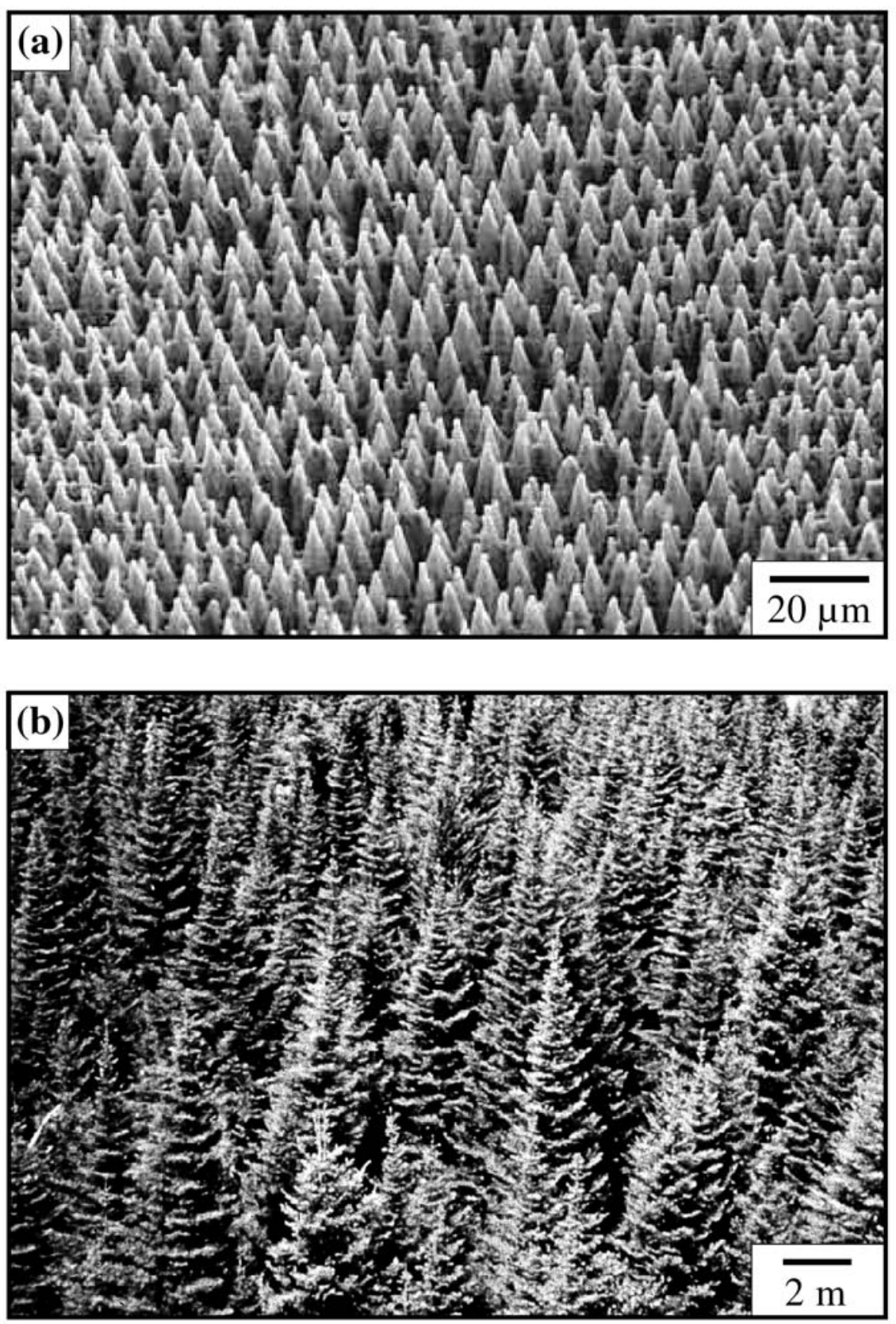

(based on the Beer-Lambert law) are inappropriate for conifer canopies.

\section{Scaling properties of conifer canopies}

Because an anechoic surface consists of a large number of cones, high absorption is an emergent property of the system (cf. Koidan et al. 1972). Scaling properties are also important in characterizing the absorptive properties of complex anechoic surfaces. Within the PAR spectrum, conifer and broadleaf trees have similar reflectance properties across the leaf, branch and canopy scales (Williams 1991). However, substantial differences occur in the NIR spectrum. NIR reflectance of typical laminar leaves (sugar maple) is $5-10 \%$ greater than that of conifer needles (Norway spruce, white and red pine; see also Middleton et al. 1997). At the branch and canopy scales, this difference increases to $20 \%$. Irrespective of species, conifer canopies absorb much more NIR radiation than broadleaf canopies (Ranson and Williams 1992, Brown et al. 2000).

In conifers, radiant energy scattering is scale-dependent: measurements made at the canopy scale differ from those made at the leaf and branch scales (cf. Chen 1996b). For example, measured NIR radiance declines by $30-35 \%$ 
from the leaf to canopy scales (Williams 1991). Norman and Jarvis (1975) also noted the scale-dependent nature of conifer scattering, concluding that "with the aid of hind-
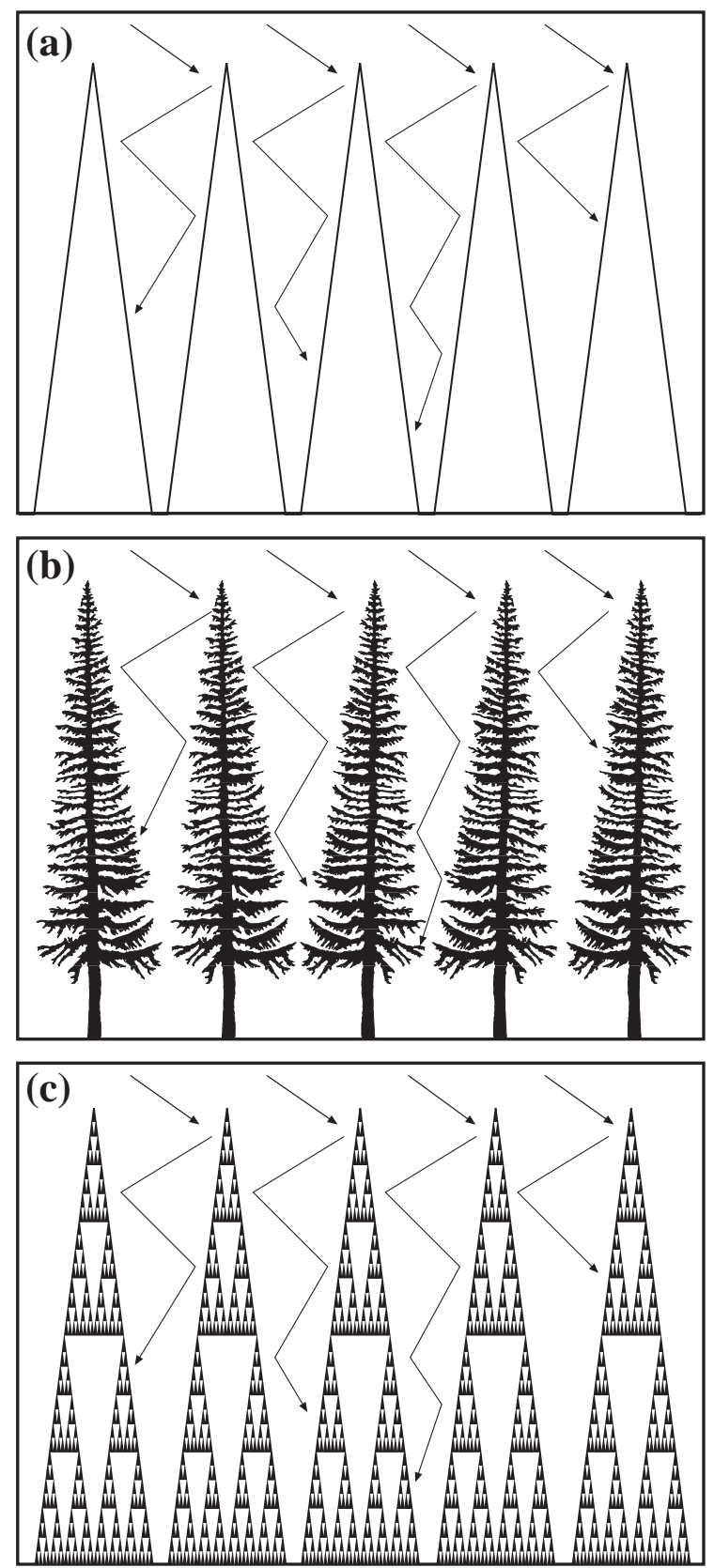

Figure 3. (a) Schematic of an idealized anechoic surface, showing multiple scattering and absorption of light (after Holloway et al. 1997); (b) A conifer stand as an anechoic surface. The conical crowns allow light to deeply penetrate the canopy, but light eventually contacts a branch/needle where it is either absorbed or scattered to another branch/needle; (c) Representation of a conifer stand as a self-similar fractal surface, illustrated using the Sierpinski gasket (Schroeder 1991). Multiscale complexity ensures that most incident solar radiance is absorbed, not reflected. sight, it is possible to suggest that the scattering properties of shoots should be measured as well as those of needles". Such findings are entirely consistent with anechoic termination.

Conceptually, a conifer stand can be viewed as a complex anechoic surface consisting of a cascading series of 'cones-on-cones' from the needle to stand scales (Fig. 3). In this sense, conifers are statistically self-similar and display fractal properties (sensu Mandelbrot 1983). We suggest that fractal iteration of the basic conical form produces a maximally absorptive (anechoic) surface from which very little incident solar radiation 'escapes' (Fig. 4). Fractal scaling has been observed in many biological systems, including conifer canopies (Zeide 1999), but specific hypotheses relating process to fractal form have not been forthcoming (Kenkel and Walker 1996). We feel that the development of a fractal surface in conifer canopies is an example of self-organization, where the conical structure is driven at all scales by the same underlying physical process of anechoic termination (cf. Perry 1995, cf. Parker 1999).

\section{Evolutionary implications}

Laminar and anechoic surfaces are fundamentally different geometric strategies for optimizing light capture. While light interception is an important aspect of the arboreal habit (King 1990), structural support, nutrient and water supply, and propagule dissemination

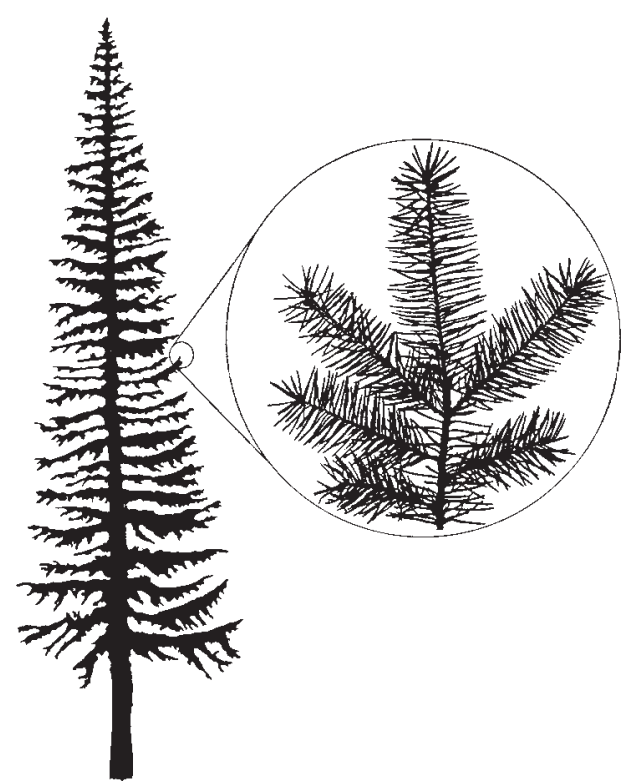

Figure 4. Self-similar scaling properties of a white spruce tree. The overall conical shape of the crown is repeated in the whorls of conical-shaped branches. The magnification illustrates similar scaling properties in the fine branches and needles. 
must also be considered (Farnsworth and Niklas 1995). Tradeoffs associated with light interception, foliar respiration, and water balance result in the selection of arboreal habits that match specific environmental conditions (Horn 1971). In this section, we consider the factors driving selection of laminar versus anechoic canopy architectures.

\section{Laminar interception}

Laminar leaf and canopy architectures are characteristic of broadleaf trees. This 'solar panel' strategy optimizes direct light interception, thus maximizing photosynthesis provided that other resources are not limiting (Bond 1989). Broadleaf trees in mesic environments typically form flat, umbrella-shaped crowns with few lower branches (Horn 1971). This results in relatively high photosynthetic efficiency and low respiration costs, since only a thin laminar canopy need be maintained (Sprugel 1989, Dalla-Tea and Jokela 1991). Thin laminar leaves are also efficient dissipaters of heat, which is of great adaptive significance in hot tropical environments (Whitmore 1990). However, a laminar architecture also results in high evapotranspiration rates, placing a strain on plants to maintain a positive water balance (Sprugel 1989). In angiosperms, advanced vessel elements and anastomosing leaf veins efficiently supply water to leaf tissue, but at a cost of increased rates of embolism under moisture stress and at low temperatures (Raven et al. 1987, Bond 1989).

Although laminar canopies are highly efficient interceptors of direct solar irradiance, light saturation in the sunleaves of temperate forest trees typically occurs at $25 \%$ of full sunlight (Horn 1971, Norman and Jarvis 1974, Sprugel 1989). Adding laminar layers increases stand photosynthetic efficiency, but shading effects may severely limit the development of a lower canopy (Horn 1971). Because laminar surfaces are highly reflective (Richards 1993), leaf transmissivity must be high enough to ensure efficient PAR absorption (Ranson and Williams 1992). Xeromorphic leaf adaptations (e.g., thick leaf cuticle), while reducing evapotranspirative water loss, also increase reflectance and so reduce light interception.

A laminar interception strategy is favoured in unevenaged, mixed-canopy stands where interspecific competition for light is strong, water is in sufficient supply, and large-scale catastrophic disturbances (e.g., crown fires) are rare. Laminar leaves and canopies are also favoured in warm-temperate to tropical environments, where solar zenith angle is high, radiant energy is direct (maximizing 'solar panel' efficiency), and ambient temperatures are high (i.e., where dissipation of heat from leaves is important).

\section{Anechoic interception}

Anechoic interception is characteristic of the gymnosperms. Conifers typically have a conical crown, maintain branches deep into the subcanopy (except in very dense stands), and have needle-like leaves. The anechoic strategy efficiently captures both direct and scattered radiant energy (cf. Sellers et al. 1995, cf. Parker 1999). Because light scatters internally within the canopy, individual needles do not need to photosynthesize or transpire at a maximal rate (Sprugel 1989). However, maintaining a high needle density in the canopy, while increasing light capture efficiency, also increases respiration costs (Sprugel 1989, King 1990). The photosynthetic efficiency of individual needles is also limited by xeromorphic traits such as thick epidermal-hypodermal layers and sunken stomata (Raven et al. 1987). Such adaptations are required in conifers because they lack efficient water conductive tissue (Raven et al. 1987, Sprugel 1989). The absence of large diameter vessel elements in conifers limits growth under mesic conditions, but at low temperatures and under high water stress xylem tracheids have a lower rate of embolism (Bond 1989).

The absorption of radiant energy in anechoic systems is structurally based, resulting in high interception of all wavelengths. Absorbed energy is ultimately emitted as heat (Van Heuvelen 1986, Sellers et al. 1995), suggesting that anechoic architecture may also be an adaptive strategy to thermally warm conifers growing in cold environments. In closed conifer stands, inner canopy temperatures may be $5-10^{\circ} \mathrm{C}$ warmer than ambient, particularly when the sun angle is low (Smith and Carter 1988). In cool-temperate environments, such thermal warming extends the effective growing season (Sprugel 1989, Smith and Brewer 1994).

A dense packing of cones increases the overall efficiency of anechoic surfaces (Holloway et al. 1997). In conifer stands, a dense canopy has the added benefit of suppressing potential competitors that may be present in the advance regeneration layer (Messier et al. 1999). Development of an efficient anechoic canopy requires that individuals be of similar size and shape, such as occurs in monodominant, even-aged stands established following a catastrophic fire. Subsequent canopy breakup and/or invasion by broadleaf species will reduce the efficiency of the anechoic canopy.

We expect the anechoic interception strategy to be selected for in environments where recurrent catastrophic 
disturbances favour the perpetuation of monodominant, even-aged conifer stands. North-temperate cloudy environments (e.g., North America's north-west coast) and other regions where the majority of incident radiation is indirect (e.g., north-facing slopes), as well as northern boreal regions where the solar zenith angle is low, will also favour anechoic over laminar interception. Anechoic properties are also favoured in cold climates, since heat energy capture rather than dissipation is paramount. Finally, conifers may be favoured in temperate xeric environments where water rather than light is the limiting factor.

\section{Implications for biophysical indices}

\section{Canopy transmissivity, LAI and productivity}

Anechoic interception provides a ready explanation for conflicting data on conifer canopy transmissivity. While some studies have found that conifer canopy transmittance is $<1 \%$ of incident irradiance (Norman and Jarvis 1974, Ranson and Williams 1992), others have recorded deep penetration of diffuse irradiance into the canopy (Gholz et al. 1991, Rowe 1993, Sampson and Smith 1993). Conical branch and tree architecture in conifers ensures high transmittance between structural elements, with the result that light may penetrate well into the canopy (Sampson and Smith 1993, Canham et al. 1999). However, once the incident radiant energy strikes a structural element of the canopy, it is scattered until completely absorbed. Needle packing and orientation are optimized to simultaneously increase transmissivity into, and absorption by, the canopy (Sprugel 1989). Given the structural complexity of conifers, it is clear that a single measure of transmissivity cannot quantify inherent heterogeneity of the anechoic surface (cf. Chen 1996b). The importance of this assertion cannot be understated, as LAI is often determined indirectly from canopy transmissivity data (Lieffers et al. 1999).

Indirect estimates of LAI are commonly used to model canopy radiative transfer (Norman and Jarvis 1975, Lieffers et al. 1999). Indirect methods for estimating LAI work well in broadleaf canopies, but they consistently underestimate leaf cover in conifer stands (Ranson and Williams 1992, Chen 1996a). Empirical corrections are therefore required to obtain reasonable estimates of conifer LAI (Sampson and Smith 1993). In addition, transmissivity models based on needle properties alone are biased unless needle aggregation is also considered (Norman and Jarvis 1975, Chen 1996b, Middleton et al. 1997).

Field measurements reveal that LAI values for conifers are often 2-4 times higher than for broadleaf trees
(Sprugel 1989). Numerous authors have suggested that high needle density results in self-shading, reducing canopy photosynthetic efficiency (Gholz et al. 1991, DallaTea and Jokela 1991, Sampson and Smith 1993). However, this assertion is inconsistent with empirical data: conifer productivity often equals or exceeds that of broadleaf trees under similar climatic conditions (Sprugel 1989). This paradox has been explained by 'shadowing' within the canopy: while conifers do indeed cast a deep shade, they also absorb virtually all incident radiation (Ranson and Williams 1992, Rowe 1993, Hall et al. 1995, Sellers et al. 1995). We suggest that 'shadowing' is the product of an adaptively efficient anechoic surface consisting of densely-packed needles arranged so as to maximize radiant energy 'capture'.

\section{Vegetation indices}

Anechoic scattering by conifer canopies has important implications for the interpretation of vegetation indices derived from remotely sensed data. Commonly used indices express PAR and NIR spectral band values as a ratio (Myers 1983, Chen 1996a). Spectral band ratioing, which is often used to predict primary productivity, is based on two assumptions: that leaf pigments differentially absorb visible light (PAR), and that NIR reflectance increases as phytomass increases (Ranson and Williams 1992, Chen 1996a). Thus, productive habitats are expected to have low PAR radiance but high NIR radiance (Tucker 1979, Myers 1983). The 'simple ratio' (SR) vegetation index, originally developed for tropical forests (Jordan 1969), uses this assumed relationship:

$S R=N I R / P A R$

where the units of reflected PAR and NIR energy are in $\mathrm{W} / \mathrm{m}^{2} / \mathrm{ster} / \mu \mathrm{m}$. Higher SR values are assumed to indicate greater photosynthetic efficiency. Because it is a simple ratio, the SR index is unbounded. Furthermore, it is sensitive to non-selective atmospheric scattering (so-called Mie scattering), variations in aspect, and incidence angle (Colwell 1974, Tucker 1979, Richards 1993). Proportional differences in magnitude are thus assumed to reflect 'noise' that should be corrected for through normalization. The 'normalized difference vegetation index' (NDVI) was originally developed to measure phytomass/productivity in North America's Great Plains grasslands (Rouse et al. 1973):

$N D V I=\frac{N I R-P A R}{N I R+P A R}$

NDVI is normalized to range between -1 and +1 , but 
negative values are uncommon (Blair and Baumgardner 1977). Although developed to estimate grassland production (Rouse et al. 1973, Myers 1983), NDVI has been uncritically applied across various ecosystems, e.g., to estimate global primary productivity (Los et al. 1994, Prince and Goward 1995).

NDVI has been successfully used to quantify spatial and temporal changes in phytomass and/or productivity across broadly-defined vegetation classes: examples include changes in LAI along a moisture gradient from interior high desert to wet coastal forest (Peterson et al. 1987), grassland productivity along a gradient from bare ground to complete vegetation cover (Paruelo et al. 1997), and tree density over a range of $0-50 \%$ canopy closure (McDonald et al. 1998). However, there are some problems inherent in applying NDVI to boreal forest ecosystems (Chen 1996a). Indeed, the relationship between NDVI and phytomass/LAI is largely invariant once canopy closure exceeds a critical threshold (McDonald et al. 1998, Ranson and Williams 1992).

To further investigate the behaviour of NDVI, we examined the reflectance properties of grassland, shrubland, and boreal broadleaf and conifer forest in Riding Mountain National Park (RMNP), Canada. A LANDSAT-5 thematic mapper image of the region dated August 3, 1991 was used. This image was selected for its high atmospheric transmittance and minimal cloud cover. The spectral ranges used to calculate NDVI were $\mathrm{PAR}=0.63-0.69$ $\mu \mathrm{m}$ and NIR $=0.76-0.90 \mu \mathrm{m}$. Atmospheric effects were eliminated using a path irradiance model of $\lambda^{-4}$, which corresponds to a clear atmosphere dominated by Rayleigh scattering (Richards 1993). A dark order subtraction was then applied to correct for residual path irradiance effects (Chavez 1988). To calculate NDVI, LANDSAT-5 digital numbers were converted to absolute PAR and NIR radiance values following Markham and Barker (1986).

In the summer of 1999, $n=57$ ground sites over six vegetation classes were located at RMNP. The classes are: $I=$ grassland; $I I=$ grassland with shrubs; $I I I=$ shrubland; $I V=$ broadleaf (trembling aspen) forest; $V=$ mixed broadleaf-conifer forest (trembling aspen-white spruce); $V I=$ conifer forest, which included four canopytypes: white spruce, black spruce, balsam fir, and jack pine. Each ground site had a uniform cover and species composition over at least 1 ha. Nine ground sites were located for each of classes $I-V$. For class $V I$, three ground sites were located in each of the four canopy-types $(n=$ 12 ). Ground sites were positioned on the LANDSAT image using differentially-corrected GPS coordinates obtained in the field. PAR and NIR radiances were deter- mined from a $3 \times 3$ grid of LANDSAT pixels (approx. 1 ha) centred on each ground site.

As expected, NDVI increases with phytomass along a gradient from grasslands, through mixed grassshrublands and shrublands to closed broadleaf forests (Fig. 5a). These four vegetation classes are characterized by laminar canopy interception. NDVI values for shrublands and broadleaf forests are very similar ( $0.83 \mathrm{vs.}$ $0.85)$, despite the forests having much higher phytomass. This result is largely attributable to lower NIR backscattering from the forests, which is contrary to expectation: NDVI implicitly assumes that PAR radiance decreases, and NIR backscattering increases, with increasing phytomass (Myers 1983). The assumed positive relationship between NIR radiance and phytomass is particularly problematic in conifers (Peterson et al. 1987, Ranson and Williams 1992). Mixed conifer-broadleaf forests and pure broadleaf forests have similar PAR reflectances, but the much lower NIR radiance of mixed forests reduces NDVI to 0.79 . Pure conifer forests reflect even less NIR, reducing NDVI to 0.73 (the same value was obtained for much less productive grass-shrubland, Fig. 5a). In fact, our results indicate that NIR radiance from conifer forests is actually lower than from grasslands.

Why is NDVI such an ineffective statistic for estimating biophysical parameters of forested ecosystems? From our empirical results, we develop a simple model of the relationship between PAR and NIR reflectance for both laminar and anechoic canopies. In laminar canopy systems, the absolute magnitude of the PAR-NIR reflectance vector remains reasonably constant as a third-dimensional physiognomic structure develops (i.e., from grassland to broadleaf forest). At the same time, the relative proportion of PAR to NIR reflectance changes in a manner consistent with the NDVI model. PAR and NIR reflectance values thus trace out an arc on the plane that corresponds to increasing phytomass (Fig. 5b). This relationship holds since laminar surface reflection is diffuse and isotropic (Richards 1993), and because laminar surfaces reflect NIR radiation in a predictable way (Myers 1983). Anechoic surfaces such as conifer canopies behave in an entirely different way: the structural arrangement of biomass scatters radiant energy (including NIR) deeper into the canopy, where it is eventually absorbed (cf. Rowe 1993). Spectral radiance (including NIR) from conifer stands is therefore very low over all wavelengths. Because NDVI isolines necessarily converge at zero, decreased NIR reflectance along a continuum from pure broadleaf to pure conifer forest results in a precipitous drop in NDVI (Fig. 5b). Our model is consistent with empirical results indicating that NDVI produces biased esti- 


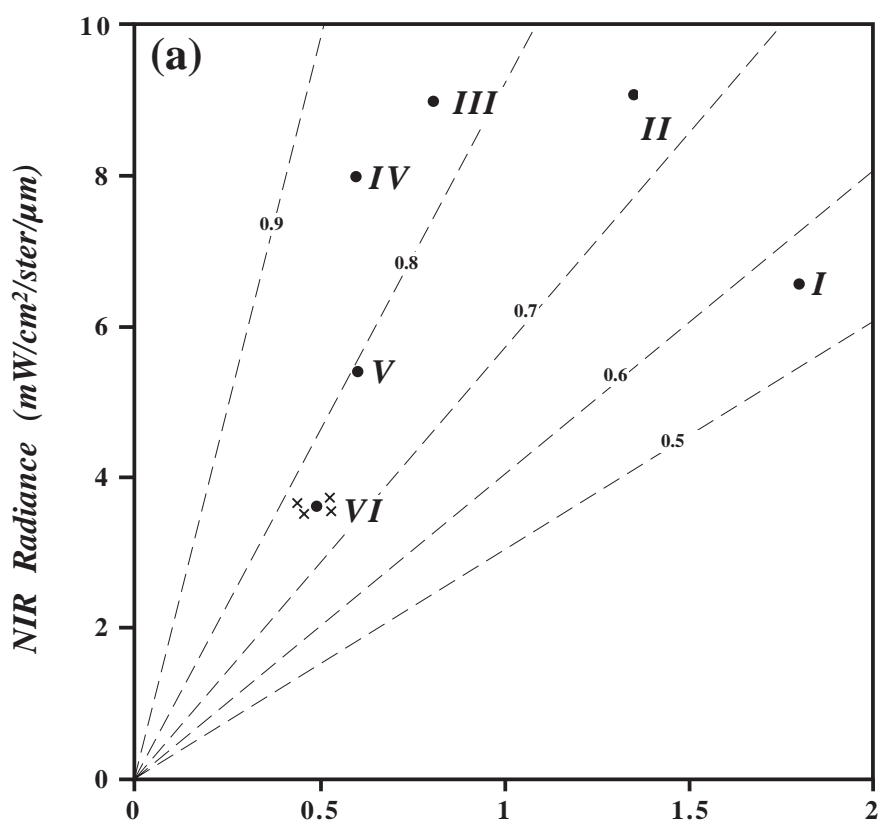

Figure 5. (a) PAR $(0.63-0.69 \mu \mathrm{m})$ and NIR $(0.76-0.90 \mu \mathrm{m})$ radiance for six vegetation classes, based on a Landsat TM image of Riding Mountain National Park: $I=$ grassland; $I I=$ grassland with shrubs; $I I I=$ shrubland; $I V=$ broadleaf forest (trembling aspen); $V=$ mixed broadleaf-conifer forest (trembling aspen-white spruce); $V I=$ conifer forest (the four $\mathrm{x}$ symbols are separate values for white spruce, black spruce, balsam fir and jackpine stands). Dashed lines are NDVI isolines; (b) A simple model of the relationship between PAR and NIR reflectance for different vegetation classes. The relationship (dark line) has two distinct trends: an arc that represents increasing NDVI as phytomass increases (grassland to shrubland to broadleaf forest), and a considerable decline in NIR radiance when conifers enter the canopy.

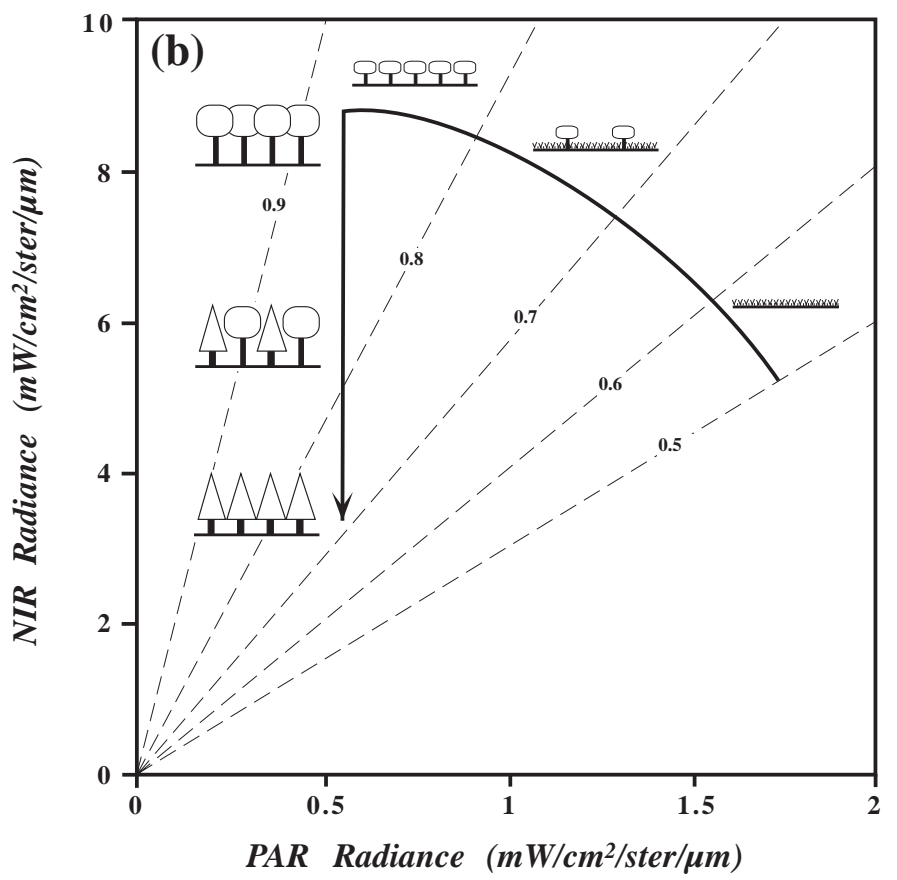

mates of phytomass/productivity in closed forest ecosystems, particularly when conifers are present (Ranson and Williams 1992, Hall et al. 1995, McDonald et al. 1998).

Because anechoic conifer canopies have very low overall albedo, relatively small differences in NIR and/or PAR reflectance can dramatically alter spectral ratio values (cf. Myneni et al. 1992, Peterson et al. 1987). We obtained NDVI values ranging from $0.72-0.77$ for different conifer canopies, despite very small changes in absolute PAR and NIR reflectance (Fig. 5a). Even within a single conifer stand, minor changes in directional reflection can dramatically affect NDVI values (Leblanc et al. 1997).

\section{Conclusions}

Broadleaf and conifer trees have fundamentally different strategies for acquiring solar energy. Broadleaf trees employ a laminar or 'solar panel' strategy, in which flat leaves are oriented within a canopy to optimally intercept direct solar energy. By contrast, conifer trees develop a conical crown consisting of numerous overlapping branches that are densely packed with needle-like leaves. While the physiological efficiency of a laminar canopy is intuitive and widely recognized, the structural architecture of conifers seems enigmatic: a conifer canopy is nothing like a solar panel, yet the conifers as a group are 
highly successful and dominate many north-temperate regions. This paradox is resolved by viewing the conifer canopy as a highly absorptive anechoic surface. Such a surface absorbs radiant energy through repeated deflections from hierarchically-arranged structural elements. Solar energy acquisition in conifers is therefore an emergent property: while an isolated needle-leaf may not be particularly efficient, the structural arrangement of needle-leaves within the canopy produces a highly effective energy-acquiring system. The architectural geometry of conifers, characterized by a 'cone-on-cone' self-similarity from the leaf to canopy scales, is therefore highly adaptive.

Acknowledgements. This research was supported by grants from Heritage Canada (Parks) and the Natural Sciences and Engineering Research Council of Canada (NSERC) to N.C. Kenkel. We thank E. Mazur (Harvard University) for permission to use the 'black' silicon image (Fig. 2a).

\section{References}

Bégin, C. and L. Filion. 1999. Black spruce (Picea mariana) architecture. Can. J. Bot. 77: 665-672.

Beranek, L.L. and H.P. Sleeper. 1946. The design and construction of anechoic sound chambers. J. Acoust. Soc. Am. 18: 140-150.

Blair, B.O. and M.F. Baumgardner. 1977. Detection of the green and brown wave in hardwood canopy covers using multidate multispectral data from Landsat-1. Agronomy J. 69: 808-811.

Bond, W.J. 1989. The tortoise and the hare: ecology of angiosperm dominance and gymnosperm persistence. Biol. J. Linnean Soc. 36: $227-249$.

Bornkessel, C. and W. Wiesbeck. 1996. Numerical analysis and optimization of anechoic chambers for EMC testing. IEEE Trans. Electromag. Compat. 38: 499-506.

Brown, L., J.M. Chen, S.G. Leblanc and J. Cihlar. 2000. A shortwave infrared modification to the simple ratio for LAI retrieval in boreal forests: an image and model analysis. Rem. Sens. Environ. 71: $16-25$

Canham, C.D., K.D. Coates, P. Bartemucci and S. Quaglia. 1999. Measurement and modeling of spatially explicit variation in light transmission through interior cedar-hemlock forests of British Columbia. Can. J. For. Res. 29: 1775-1783.

Chavez, P.S. 1988. An improved dark-order subtraction technique for atmospheric scattering correction of mulispectral data. Remote Sens. Environ. 24: 459-479.

Chen J. M. 1996a. Evaluation of vegetation indices and a modified simple ratio for boreal applications. Can. J. Remote Sens. 22: 229-242.

Chen J. M. 1996b. Optically-based methods for measuring seasonal variation of leaf area index in boreal conifer stands. Agric. For. Meteorol. 80: 135-163.

Colwell, J.E. 1974. Vegetation canopy reflectance. Remote Sens. Environ. 3: 175-183.

Dalla-Tea, F. and E.J. Jokela. 1991. Needlefall, canopy light interception, and productivity of young intensively managed slash pine stands. For. Sci. 37: 1298-1313.

Farnsworth, K.D. and K.J. Niklas. 1995. Theories of optimization, form and function in branching architecture in plants. Funct. Ecol. 9: 355-363.
Gholz, H.L., S.A. Vogel, W.P. Cropper, K. McKelvey, K.C. Ewel, R.O. Teskey and P.J. Curran. 1991. Dynamics of canopy structure and light interception in Pinus elliottii stands, North Florida. Ecol. Monogr. 6: 33-51.

Hall, F.G., Y.E. Shimabukuro and K.F. Huemmrich. 1995. Remote sensing of forest biophysical structure using mixture decomposition and geometric reflectance models. Ecol. Appl. 5: 9931013.

Her, T.-H., R.J. Finlay, C. Wu, S. Deliwala and E. Mazur. 1998. Microstructuring of silicon with femtosecond laser pulses. Appl. Phys. Lett. 73:1673-1675.

Holloway, C.L., R.R. DeLyser, R.F. German and P. McKenna. 1997. Comparison of electromagnetic absorber used in anechoic and semi-anechoic chambers for emissions and immunity testing of digital devices. IEEE Trans. Electromag. Compat. 39: 33-46.

Horn, H.S. 1971. The Adaptive Geometry of Trees. Princeton Univ. Press, Princeton.

Jordan, C.F. 1969. Derivation of leaf-area index from quality of light on the forest floor. Ecology 50: 663-666.

Kenkel, N.C. and D.J. Walker. 1996. Fractals in the biological sciences. Coenoses 11: 77-100.

King, D.A. 1990. The adaptive significance of tree height. Am. Nat. 135: 809-828.

Klopfenstein, R.W. 1956. A transmission line taper of improved design. Proc. IRE 44: 31-35.

Koidan, W. G.R. Hruska and M.A. Pickett. 1972. Wedge design for National Bureau of Standards anechoic chamber. J. Acoust. Soc. Amer. 52: 1071-1076.

Leblanc, S.G., J.M. Chen and J. Cihlar. 1997. NDVI Directionality in boreal forests: a model interpretation of measurements. Can. J. Remote Sens. 23: 369-380.

Lieffers, V.J., C. Messier, K.J. Stadt, F. Gendron and P.G. Comeau. 1999. Predicting and managing light in the understory of boreal forests. Can. J. For. Res. 29: 796-811.

Liu, J., J.M. Chen, J. Cihlar and W.M. Park. 1997. A process-based boreal ecosystem productivity simulator using remote sensing inputs. Remote Sens. Environ. 62: 158-175.

Los, S.O., C.O. Justice and C.J. Tucker. 1994. A global $1^{\circ}$ x $1^{\circ}$ NDVI data set for climate studies derived from the GIMMS continental NDVI data. Int. J. Remote Sens. 15: 3493-3518.

Mandelbrot, B.B. 1983. The Fractal Geometry of Nature. Freeman, New York.

Markham, B.L. and J.L. Barker. 1986. Landsat MSS and TM postcalibration dynamic ranges, exoatmospheric reflectances and atsatellite temperatures. EOSAT LANDSAT Technical Notes 1: 3-8.

McDonald, A.J., F.M. Gemmell and P.E. Lewis. 1998. Investigation of the utility of spectral vegetation indices for determining information on coniferous forests. Remote Sens. Environ. 66: 250272.

Messier, C., R. Doucet, J.-C. Ruel, Y. Claveau, C. Kelly and M.J. Lechowicz. 1999. Functional ecology of advance regeneration in relation to light in boreal forests. Can. J. For. Res. 29: 812823.

Middleton, E.M., S.S. Chan, R.J. Rusin and S.K. Mitchell. 1997. Optical properties of black spruce and jack pine needles at BOREAS sites in Saskatchewan, Canada. Can. J. Remote Sens. 23: 108-119.

Myers, V.I. 1983. Remote sensing applications in agriculture. In: R. N. Colwell (ed.), Manual of Remote Sensing, Vol. II. 2nd ed. 
American Society of Photogrammetry, Falls Church, VA. pp. 2111-2228.

Myneni, R.B., G. Asrar, D. Tanre and B.J. Choudhury. 1992. Remote sensing of solar radiation absorbed and reflected by vegetated land surfaces. IEEE Trans. Geosci. Remote Sens. 30: 302-314.

Nelson, R. 1997. Modeling forest canopy heights: the effects of canopy shape. Remote Sens. Environ. 60: 327-334.

Norman, J.M. and P.G. Jarvis. 1974. Photosynthesis in sitka spruce (Picea sitchensis (Bong.) Carr.): III. Measurements of canopy structure and interception of radiation. J. Appl. Ecol. 11: 375398 .

Norman, J.M. and P.G. Jarvis. 1975. Photosynthesis in sitka spruce (Picea sitchensis (Bong.) Carr.): V. Radiation penetration theory and a test case. J. Appl. Ecol. 12: 839-878.

Norman, J.M. and J.M. Welles. 1983. Radiative transfer in an array of canopies. Agronomy J. 75: 481-488.

Parker, A.R. 1999. Light-reflection strategies. Am. Sci. 87: 248-255.

Paruelo, J.M., H.E. Epstein, W.K. Lauenroth and I.C. Burke. 1997. ANPP estimates from NDVI for the central grassland region of the United States. Ecology 78: 953-958.

Perry, D.A. 1995. Self-organizing systems across scales. Trends Ecol. Evol. 10: 241-244.

Peterson, D.L., M.A. Spanner, S.W. Running and K.B. Teuber. 1987. Relationship of thematic mapper simulator data to leaf area index of temperate coniferous forests. Remote Sens. Environ. 22: 323-341.

Pierce, A.D. 1981. Acoustics: An Introduction to its Physical Principles and Applications. McGraw-Hill, New York. 642 pages.

Prince, S.D. and S.N. Goward. 1995. Global primary production: a remote sensing approach. J. Biogeogr. 22: 815-835.

Ranson, K.J. and D.L. Williams. 1992. Remote sensing technology for forest ecosystem analysis. In: H. H. Shugart, R. Leemans and G.B. Bonan (eds.), A Systems Analysis of the Global Boreal Forest. Cambridge U. Press, Cambridge. pp. 267-290.

Raven, P.H., R.F. Evert and S.E. Eichhorn. 1987. Biology of Plants. 4th ed. Worth, New York.

Richards, J.A. 1993. Remote Sensing Digital Image Analysis: An Introduction. 2nd ed. Springer-Verlag, New York.
Rouse, J.W., R.H. Haas, J.A. Schell and D.W. Deering. 1973. Monitoring vegetation systems in the Great Plains with ERTS. Third ERTS Symposium, NASA SP-315 I: 309-317.

Rowe, C.M. 1993. Incorporating landscape heterogeneity in land surface albedo models. J. Geophys. Res. 98: 5037-5043.

Sampson, D.A. and F.W. Smith. 1993. Influence of canopy architecture on light penetration in lodgepole pine (Pinus contorta var. latifolia) forests. Agric. For. Meteorol. 64: 63-79.

Schroeder, M. 1991. Fractals, Chaos, Power Laws: Minutes from an Infinite Paradise. Freeman, New York.

Sellers, P., F. Hall, H. Margolis, B. Kelly, D. Baldocchi, J. den Hartog, J. Cihlar, M. Ryan, B. Goodison, P. Crill, J. Ranson, D. Lettenmaier and D. Wickland. 1995. The Boreal EcosystemAtmosphere Study (BOREAS): an overview and early results from the 1994 field year. Bull. Am. Meteorol. Soc. 76: 15491577.

Smith, W.K. and C.A. Brewer. 1994. The adaptive importance of shoot and crown architecture in conifer trees. Am. Nat. 143: 528532.

Smith, W.K. and G.A. Carter. 1988. Shoot structural effects on needle temperatures and photosynthesis in conifers. Am. J. Bot. 75: 496-500.

Sprugel, D.G. 1989. The relationship of evergreenness, crown architecture, and leaf size. Am. Nat. 133: 465-479.

Tomlinson, P.B. 1983. Tree architecture. Am. Sci. 71: 141-149.

Tucker, C.J. 1979. Red and photographic infrared linear combinations for monitoring vegetation. Remote Sens. Envir. 8: 127-150.

Van Heuvelen, A. 1986. Physics: A General Introduction. Little, Brown \& Co., Toronto.

Williams, D.L. 1991. A comparison of spectral reflectance properties at the needle, branch, and canopy level for selected conifer species. Remote Sens. Environ. 35: 79-93.

Whitmore, T.C. 1990. An Introduction to Tropical Rain Forests. Oxford Univ. Press, Oxford.

Zeide, B. 1999. Fractal analysis of foliage distribution in loblolly pine crowns. Can. J. For. Res. 28: 106-114. 


\title{
Announcement
}

International statistical ecology conference

\section{Diversity, complexity, abundance, resemblance, scale dependence: Theories, methods, applications}

\section{(ABUDIV 2001)}

\author{
Balatonfüred, Hungary, \\ August 28 - September 2, 2001
}

\section{Motivation}

The title topics have been discussed many times in publications and at conferences in contexts ranging from the environmental to the zoological, botanical and beyond. The related theory and applications have evolved through many important findings in recent years and became ripe to be made the subject of open discussions at a statistical ecology conference which will focus on the notions, their inter-connectedness, related methodologies, mathematical con-cepts and the practical implications for governance and amelioration programs.

Some highlighted topics from the scientific program

- Model oriented approaches to diversity and the mathematical aspects of diversity indices.

- Hierarchical diversity and complexity: an emergent characteristic of communities.

- Abundance distributions and rank abundance curves.

- Statistical aspects of resemblance (similarity) and beta-diversity.

- Scale dependence of pattern perception.

- Syndynamic implications of self-similarity.

Submission of abstracts and manuscripts

The language of the conference and in all published materials is English. Abstracts should be prepared and submitted in rich text format (RTF) as an attachment to an e-mailed cover letter or on PC diskette; a hard copy is also required, sent by mail or fax to the following address:

Dr. B. Tóthmérész

Department of Ecology, University of Debrecen

P.O. Box 71

H-4010 Debrecen, Hungary

Fax: +36 52431148

e-mail: tothmerb@terra.ecol.klte.hu

Conference web site

Continuous access to updated congress information is provided through the web site

http://www.terra.hu/abudiv/index.html 